\title{
Mechanical behavior of adhesive anchors under high temperature exposure: Experimental investigation
}

\author{
Mohamed Amine Lahouar ${ }^{\mathrm{a}, \mathrm{b}, *}$, Jean-François Caron ${ }^{\mathrm{a}}$, Nicolas Pinoteau $^{\mathrm{b}}$, Gilles Forêt ${ }^{\mathrm{a}}$, Karim \\ Benzartic
}

${ }^{a}$ Université Paris-Est, Laboratoire Navier (UMR 8205), Ecole des Ponts ParisTech, F-77455 Marne-

la-Vallée, France

${ }^{\mathrm{b}}$ Centre Scientifique et Technique du Bâtiment, 77420 Champs-sur-Marne, France

c Université Paris-Est, Département Matériaux et Structures, IFSTTAR, 14-20 Boulevard Newton,

77420 Champs-sur-Marne, France

*Corresponding author. Tel: +33630242016. E-mail address: amine.lahouar@enpc.fr. Present address: 6-8 Avenue Blaise Pascal, Ecole Nationale des Ponts et Chaussées, 77420 Champs-surMarne, France.

\begin{abstract}
The improvement in mechanical and adhesion properties of polymer resins have allowed to progressively substitute cast-in place rebars by polymer-based anchors in some applications, by providing equivalent or even higher mechanical properties at ambient temperature. However, a temperature increase has the effect of weakening the bond and leads to a significant decay in the bearing capacity of the adhesive anchors.

This paper presents a study of the phenomena that occur at high temperature in an adhesive anchor when exposed to high temperatures by means of two pull-out test procedures and by thermomechanical characterization of the polymer resin. Results showed that the resin glass transition is the responsible for the decay in the fire resistance of adhesive anchors. The paper highlights the non-conservative aspect of the current design method used to calculate the fire resistance of chemical anchors and proposes to consider the pull-out curves as input data.
\end{abstract}

Keywords: Chemical anchor; Fire resistance; Epoxy adhesive; Glass transition temperature; Pull-out tests; Design method.

\section{Introduction}

The epoxy resin was discovered for the first time by Pierre Castan in 1936 [1]. Its applications were restricted to industrial purposes until 1955. Since then, epoxy resins were used in almost every industrial purposes and even in bridges construction in USA and then in Paris in 1963 [2]. Over the years, the use of epoxy resins in concrete structures was constantly increasing for different applications such as cracks and joints filling, bonding concrete to concrete, metal to metal and steel to concrete [3]. The use of epoxy resins in bonding steel to concrete, and more specifically in bonding steel rods into already existing reinforced concrete, had offered a multitude of possibilities for retrofitting, extension and reparation of existing structures [4] [5]. Post-installed rebars using epoxy resins have then allowed to substitute cast-in-place rebars by offering equivalent or even higher bearing capacities at service temperature [6] [7].

Over the past two decades, several experimental research work has been conducted in order to determine the different parameters affecting the mechanical properties of bonded post-installed rebars by means of pull-out tests [8] [9]. Numerous researchers were interested in the study of the relationship between the geometry of the chemical anchor and its mechanical behavior. These studies showed that the load bearing capacity increases linearly by increasing the embedment length up to $75 \mathrm{~mm}$ for anchors diameter equal to $10 \mathrm{~mm}$ and that the bond strength reaches its maximum when the bond thickness is equal to $2 \mathrm{~mm}$ [10]. More precisely, there is less risk of creep failure when the diameter of the hole is close to the rod diameter [11]. Design documents have been developed based on these studies in order 
to ensure a minimum level of safety when using chemical anchors, equivalent to that for cast-in-place rebars [12].

Other researchers were interested in the study of the environmental effects on the mechanical behavior of chemical anchors. Obtained results showed that the load bearing capacity of chemical anchors depends on the atmosphere to which the anchor is subjected [13] [14]. A particular attention was paid to the study of the mechanical behavior of chemical anchors at high temperature due to the sensitivity of polymer resins to elevated temperatures. In fact, the major problem with polymer resins was viscosity, which is responsible for creep phenomenon at high temperature [15] [16]. Studies had shown that epoxy resins have generally a constant stiffness up to $50^{\circ} \mathrm{C}$ [17]. However, several epoxy resins used in civil engineering melt between $20^{\circ} \mathrm{C}$ and $80^{\circ} \mathrm{C}$. This means that the glass transition of these resins may occur during their service lifetime [18]. Studying the mechanical behavior of an adhesive joint at different temperatures is therefore necessary to determine the temperature range in which it can provide its maximum bond strength [19].

Very few regulations and technical documents exist today proposing methods to assess and to design chemical anchors at high temperature:

The CFA Guidance Note [20] proposes to measure the fire resistance of chemical anchors by performing pull-out tests under ISO 834-1 fire exposure [21]. The obtained results depend on the anchor diameter, the distance between the anchors, the distance to the edge and the applied tensile load. If the measured fire resistance is not satisfactory, the document proposes to increase the embedment length, which permit to delay the temperature increase along the anchor and consequently increases the fire resistance duration.

Some research studies [22] showed that it is possible to design post-installed rebars according to the Eurocode 2 method (section 8.4.2) [23] proposed for cast-in-place rebars, since both anchoring systems can develop equivalent mechanical performances at ambient temperature [6] [7]. However, this design method cannot be used anymore when chemical anchors are subjected to fire, due to the significant decay in the mechanical properties of the resin at high temperature. Nevertheless, Muciaccia et al. [24] proposes a design method for chemical anchors in fire situation, based on the Eurocode 2 design method, by introducing a reduction factor $k_{f i}(\theta)$ allowing to adjust the bond strength depending on temperature (1).

$$
k_{f i}(\theta)=\tau_{m}(\theta) / f_{b m, r q d} \leq 1
$$

Where,

- $\quad k_{f i}(\theta)$ is a reduction factor at increased temperature

- $\tau_{m}(\theta)$ is the bond strength at the temperature $\theta$

- $f_{b m, r q d}$ is the required bond strength (10 MPa for cast-in-place rebars)

The bond strength of post-installed rebars is thus calculated by multiplying the bond strength at $20^{\circ} \mathrm{C}$ by the reduction factor $k_{f i}(\theta)$ following equation (2).

$$
f_{b d}(\theta)=k_{f i}(\theta) \cdot f_{b d\left(20^{\circ}\right)} / \gamma_{M, f i}
$$

Where,

- $\quad f_{b d}(\theta)$ is the bond strength at the temperature $\theta$

- $f_{b d\left(20^{\circ} \mathrm{C}\right)}$ is the bond strength at $20^{\circ} \mathrm{C}$, equal to $2.3 \mathrm{MPa}$ according to Eurocode 2 [23]

- $\quad \gamma_{M, f i}$ is a material safety factor in case of fire exposure, taken equal to 1.0 
The EAD (European Assessment Document) [25] proposes to assess the fire resistance of chemical anchors by performing pull-out tests at constant load on post-installed rebars bonded into confined concrete cylinders. The design method consists in describing the decay in the bond resistance under heating effect by fitting the bond resistance vs anchor temperature curve by an exponential trend function if the measured bond strength is less than $10 \mathrm{MPa}$, and by cutting the curve at $10 \mathrm{MPa}$ if the measured bond strength is greater than or equal to $10 \mathrm{MPa}$, as described in (3).

$$
f_{b m}(\theta)=\left\{\begin{array}{lll}
a \cdot \exp (-\mathrm{b} . \theta) & \text { if } & f_{b, t e s t}<10 \mathrm{MPa} \\
10 \mathrm{MPa} & \text { if } \quad f_{b, t e s t} \geq 10 \mathrm{MPa}
\end{array}\right.
$$

Where,

- $\quad f_{b, t e s t}$ is the bond strength measured by pull-out test

- $f_{b m}(\theta)$ is the mean bond resistance at the temperature $\theta$

- $\quad a, b$ are the exponential fitting curve constants

This paper complements these existing documents by proposing and comparing between two test methods allowing to assess the mechanical behavior of chemical anchors at high temperature. The first method called "pull-out tests at stabilized temperature", consists in heating the anchor to a target temperature and then applying a tensile stress until the total extraction of the rebar. While the second method, called "pull-out tests at constant load", consists on applying a constant tensile load to the anchor and then heating the test specimen until failure. The goal of this paper is to explain the difference in results between these two test procedures by interpreting the physical, chemical and mechanical phenomena that occur at high temperatures at the scale of the materials and at the scale of the anchor. This paper draws a specific attention to the non-conservative aspect of designing rules proposed today by existing documents for the fire safety of chemical anchors.

The first part of this paper focuses on the study of the temperature effects on physical, chemical and mechanical properties of the resin, and on the description of the experimental procedures chosen to study the mechanical behavior of post-installed rebars at high temperature. While the second part is devoted to the comparison between the two test procedures and to the study of the temperature effects on the stiffness and on the failure mode of chemical anchors. The paper concludes with a critique of the nonconservative aspect of the current design methods and by suggesting solutions for a safer design of chemical anchors in fire situation.

\section{Materials and experimental procedure}

\subsection{Specimen}

Three materials: steel bar, concrete and epoxy resin, were used in this work.

The steel bar used was a $12 \mathrm{~mm}$ Diwidag type rebar, anchored in the concrete with two different embedment lengths: 40 and $60 \mathrm{~mm}$ (Table 2 and Table 3). The Young's modulus measured by tensile tests was Es= $222 \mathrm{GPa}$ (Figure 1). The ultimate tensile stress value and the yield stress value were determined $\left(\sigma_{u t s}=680 \mathrm{MPa}, \sigma_{y}=560 \mathrm{MPa}\right)$. The surface of the steel rebar was then degreased using acetone before being anchored in order to remove impurities that may disturb the adhesion with concrete. 


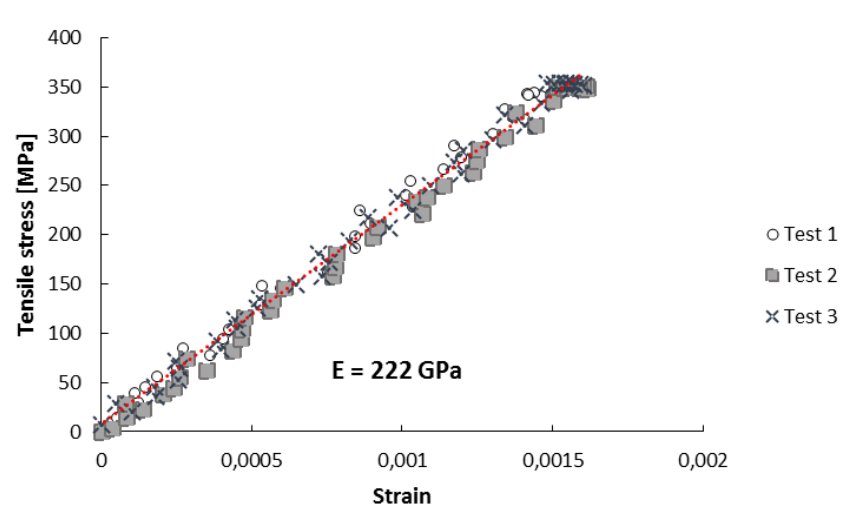

Figure 1: Tensile tests on $12 \mathrm{~mm}$ diameter Diwidag rebar

The concrete specimen was a cylinder ( $16 \mathrm{~cm}$ diameter, $25 \mathrm{~cm}$ height), bordered by a $2 \mathrm{~mm}$ thick steel layer to avoid cracks on the exterior lateral side of the cylinder. The concrete had an average compressive strength $27.8 \mathrm{MPa}$ at 28 days, determined by compressive tests performed on concrete cubes. Cylinders used for testing had been cured for more than two months in the laboratory conditions $\left(20^{\circ} \mathrm{C}, 65 \% \mathrm{RH}\right)$ after being cured for 28 days at ambient moisture and temperature.

The selected adhesive was a bi-component epoxy resin. At least two days were left for the mortar to cure in laboratory conditions before performing tests.

The anchor hole was drilled in the center of the hardened concrete cylinder just before the resin injection and was cleaned according to the resin supplier's indications. The diameter of the hole was $4 \mathrm{~mm}$ larger than the rebar diameter in order to get $2 \mathrm{~mm}$ thick adhesive layer, and $20 \mathrm{~mm}$ deeper than the embedment length to reduce heat loss. Indeed, moving the embedded part away from the concrete surface allow to reduce thermal losses and consequently allow to reach more quickly the desired temperatures when heating. In addition, an adhesive tape was applied on the free part of the anchor, as described in Figure $\underline{2}$, in order to break the adhesion on the free part, to set the exact embedment length and to decrease the stress concentration at the top of the anchor [26].

Two thermocouples were installed in the embedded part of the steel rebar: At the deepest part of the anchor (TC1) and at $10 \mathrm{~mm}$ from the top of the embedded part (TC2) (Figure 2). These two thermocouples measured the temperature along the rebar embedded part during pull-out tests.

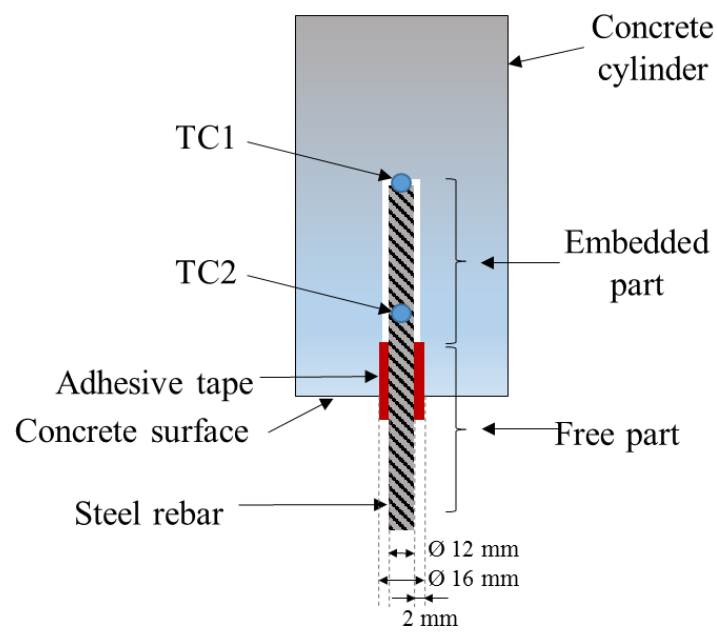




\subsection{Temperature effects on physical and chemical properties of the resin}

\subsubsection{Thermo-Gravimetric analysis (TGA)}

A TGA test was performed on a small sample of the epoxy resin ( $3 \mathrm{~mm} \times 3 \mathrm{~mm} \times 2 \mathrm{~mm}$ ) used for pullout tests. The test procedure consisted in measuring the mass loss of the resin sample during heating from $20^{\circ} \mathrm{C}$ to $800^{\circ} \mathrm{C}$ with $20^{\circ} \mathrm{C} / \mathrm{min}$ heating rate. The purposes of this test were to determine the temperature of deterioration of the material and to estimate the amount of mineral charges contained in the resin. The initial mass of the resin sample was $51.3 \mathrm{mg}$.

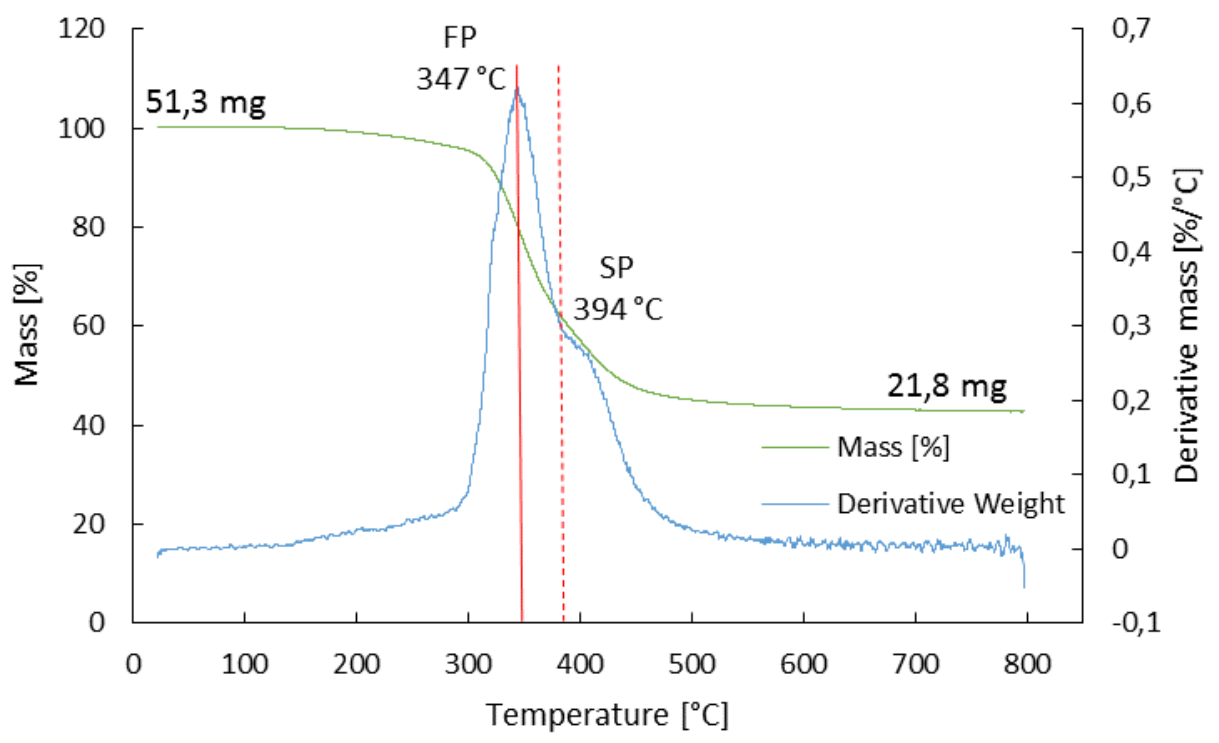

Figure 3: Mass loss and derivative mass loss Vs resin temperature curve

Curves in Figure 3 show the mass variation and its derivative versus the heating temperature. Results obtained from TGA test show $57.6 \%$ of mass loss between $20^{\circ} \mathrm{C}$ and $800^{\circ} \mathrm{C}$. The mass loss curve highlights a rapid decrease in the sample mass starting from $320^{\circ} \mathrm{C}$ followed, by an inflection point at $347^{\circ} \mathrm{C}$, identified through a first peak (FP) on the derivative mass curve. This first peak (FP) could indicate the oxidation of the tested material, while the second peak at $394^{\circ} \mathrm{C}(\mathrm{SP})$ may reflect changes in the chemical composition of the resin under heat effect. The remaining mass at the end of the test represents $42.4 \%$ of the sample's initial mass. This remaining mass is composed of ashes and essentially of silica added to the resin in order to increase its mechanical properties [1].

TGA test results show a negligible mass loss between $20^{\circ} \mathrm{C}$ and $150^{\circ} \mathrm{C}$, equal to $0.1 \mathrm{mg}$, representing $0.2 \%$ of the initial mass of the resin. This mass loss can be attributed to the vaporization of water contained in the resin components and does not reflect any change in the chemical composition of the resin.

In conclusion, from TGA test results, one can confirm that no changes in the resin chemical composition has taken place during pull-out tests (between $20^{\circ} \mathrm{C}$ and $150^{\circ} \mathrm{C}$ ).

\subsubsection{Differential Scanning Calorimetric test (DSC)}

A DSC test campaign was carried out on the epoxy resin used for pull-out tests in order to determine its glass transition temperature, to highlight the presence of post-cure phenomenon and to study the preheating influence on the crosslinking degree of the polymerization reaction. 
Four resin samples were prepared for the DSC test. Three of these four samples were preheated at various temperatures as described in Table 1, and then cooled to ambient temperature for 72 hours before performing the tests.

The DSC test procedure consisted in heating the resin samples up to $200^{\circ} \mathrm{C}$ with a $20^{\circ} \mathrm{C} / \mathrm{min}$ heating rate, measuring the heat flow released or absorbed during heating and compare it with a reference sample (empty crucible).

\begin{tabular}{cc}
\hline $\begin{array}{c}\text { Conditioning } \\
\text { temperature }\end{array}$ & $\begin{array}{c}\text { Conditioning } \\
\text { time }\end{array}$ \\
\hline $20^{\circ} \mathrm{C}$ & - \\
(Ambient temperature) & $3 \mathrm{~h}$ \\
$50^{\circ} \mathrm{C}$ & $3 \mathrm{~h}$ \\
$82^{\circ} \mathrm{C}$ & $3 \mathrm{~h}$ \\
$108^{\circ} \mathrm{C}$ & \\
\hline Table 1: Conditioning properties of test specimens
\end{tabular}

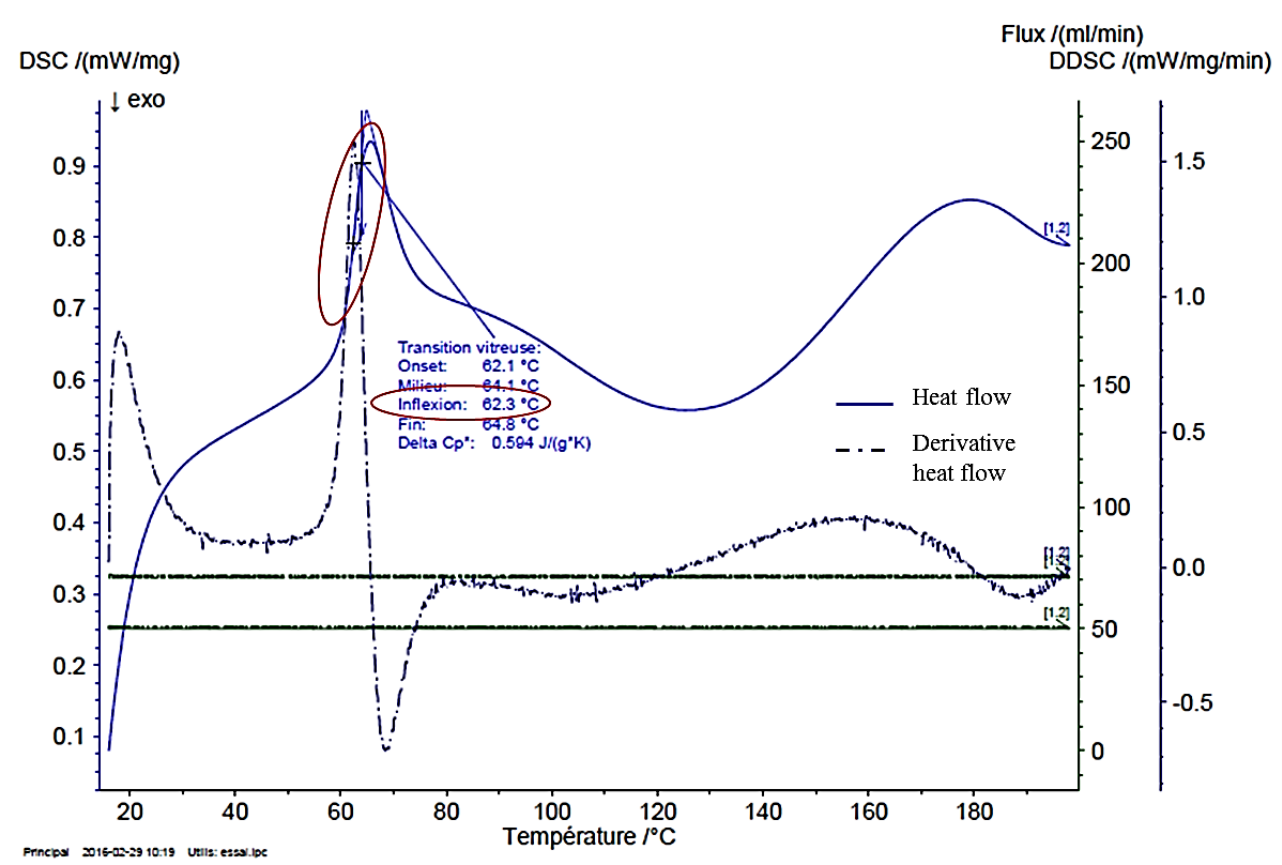

Figure 4: Heat flow vs heating temperature curve for resin sample cured at room temperature

Results obtained from the DSC test machine were curves showing the difference in variation of the heat flow between the test sample and the reference during heating. Figure 4 shows the test results of the epoxy resin sample cured at room temperature. The solid curve shows the heat flow variation between $20^{\circ} \mathrm{C}$ and $200^{\circ} \mathrm{C}$. This curve presents an endothermic peak between $60^{\circ} \mathrm{C}$ and $80^{\circ} \mathrm{C}$, reflecting an important absorption of energy and indicating a possible change in the physical state of the resin. Therefore, the glass transition temperature must be between these two temperatures. In fact, the glass transition temperature is defined as the temperature at which the physical state of the resin changes from the hard state into the molten state.

To determine the precise value of the glass transition temperature, the inflection point method described in [27] was adopted. This method consists in determining the position of the inflection point on the heat flow variation curve, and considering the corresponding temperature as the sample glass transition temperature. The position of the inflection point has been easily identified thanks to the derivative curve of the heat flow (dashed line). Thus, the right position of the inflection point corresponds to the position 
of the maximum of the dashed curve. By applying this method, it was possible to determine the glass transition temperature value for each sample tested, as reported in Figure 5.

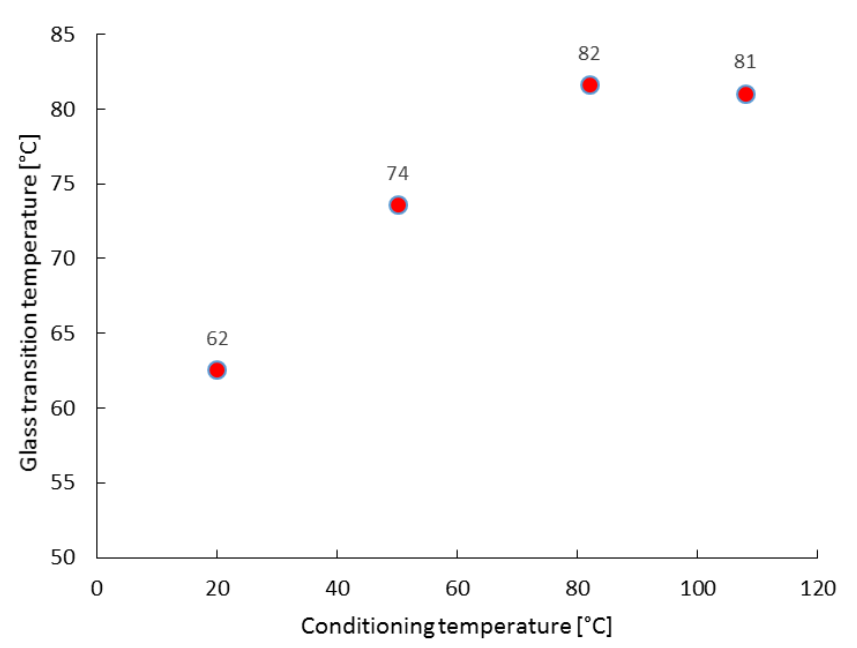

Figure 5: Glass transition temperature Vs conditioning temperature

Without thermal conditioning, results show that for a polymerized resin at room temperature, the glass transition temperature is around $62^{\circ} \mathrm{C}$. This glass transition temperature increases gradually by increasing the conditioning temperature until reaching a maximum value around $82^{\circ} \mathrm{C}$. At this stage, the glass transition temperature remains constant and becomes independent on the thermal history of the material.

The DSC curves revealed also the presence of an exothermic heat flow between $90^{\circ} \mathrm{C}$ and $170^{\circ} \mathrm{C}$. The amplitude and the duration of the exothermic heat flow decreased by increasing the sample conditioning temperature. The release of an exothermic flow indicates a reaction between the hardener and the resin, and therefore indicates the presence of a post-cure phenomenon. The decrease in the amplitude and the duration of the exothermic heat flow when the conditioning temperature increases can be explained by the progress of the polymerization reaction upon heating. Thus, the more the reaction approaches to its maximum crosslinking degree (reached at high temperature), the more the amount of reagent mixture is low, producing consequently a lower exothermic peak.

By measuring the difference of the quantity of heat flow released and absorbed between the exothermic and endothermic peaks on each profile, it was possible to establish a comparison criterion to compare the degrees of crosslinking of the polymerization reaction for the different conditioning temperatures. Results obtained are shown in Figure 6.

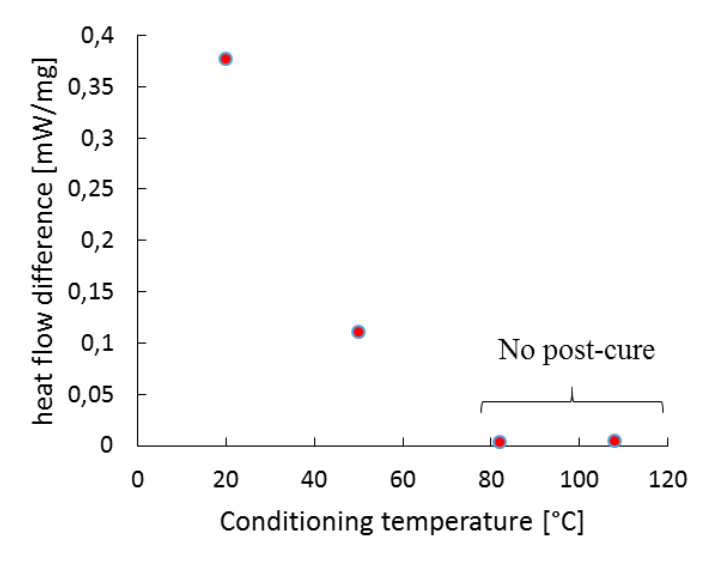

Figure 6: Post-cure peaks Vs conditioning temperature 
The results comparison have shown a decrease in the quantity of heat flow released and absorbed when conditioning temperature increases. The resin cured at room temperature had the largest quantity of exchanged heat flow among the four samples tested. This result indicates that this resin sample presents the lowest degree of crosslinking. Figure 6 shows that the samples preheated at $82^{\circ} \mathrm{C}$ and $108^{\circ} \mathrm{C}$ have a similar amount of exchanged heat flow, which is close to zero. This results confirm that for these two resin samples, the polymerization reaction had almost reached its maximum degree of crosslinking. Therefore, practically no post-cure phenomenon could be observed on these two samples and consequently the heating of these two samples during the DSC test could no longer contribute to the advancement of the polymerization reaction.

In conclusion, DSC tests have shown that there is a curing temperature, less than or equal to $82^{\circ} \mathrm{C}$, at which the resin reaches its maximum degree of crosslinking.

\section{3 pull-out test procedures}

Pull-out tests were performed in a heated environment by applying a tensile load to the rebar using a hydraulic jack.

The concrete cylinder was positioned above a large $20 \mathrm{~mm}$ thick confinement steel plate, containing 4 holes: A central $20 \mathrm{~mm}$ diameter big hole, through which passed the rebar, and three small holes (10 $\mathrm{mm}$ diameter) designed for displacement sensors. This confinement steel plate was placed above three cylindrical hard steel supports. The connection between the jack and the specimen was ensured by a nut, which transmitted the tensile force to the rebar (Figure 7).

As described in the introduction, two test procedures were performed to study the mechanical behavior of chemical anchors at high temperature:

- Pull-out tests at stabilized temperature: This test procedure was used by Pinoteau [28] and by Muciaccia et al. [24] in order to determine a bond strength capacity for selected target temperatures. The procedure consists in heating the concrete cylinder until the temperature measured by TC1 and TC2 reaches the target temperature and remains constant for at least 2 hours. After that, a tensile load is applied until the debonding of the steel rebar.

This test procedure was performed for different target temperatures ranging from $16^{\circ} \mathrm{C}$ to $130^{\circ} \mathrm{C}$.

- Pull-out tests at constant load: This test procedure is provided by the EOTA [25] and consists in applying a constant load before heating the specimen. Once the target load is reached, the specimen is heated progressively up to the failure point, determined by the extraction of the steel rebar. The failure temperature is considered as the mean value of TC 1 and TC 2. These tests were carried out with different loads ranging from $7 \mathrm{kN}$ to $41 \mathrm{kN}$.

For each test procedure, the rebar displacement was measured through three Linear Variable Differential Transformer (LVDT) sensors, positioned at $63 \mathrm{~mm}$ below the concrete surface. The sensors measured the relative displacement between the concrete surface and the rebar (at $63 \mathrm{~mm}$ of free length). 


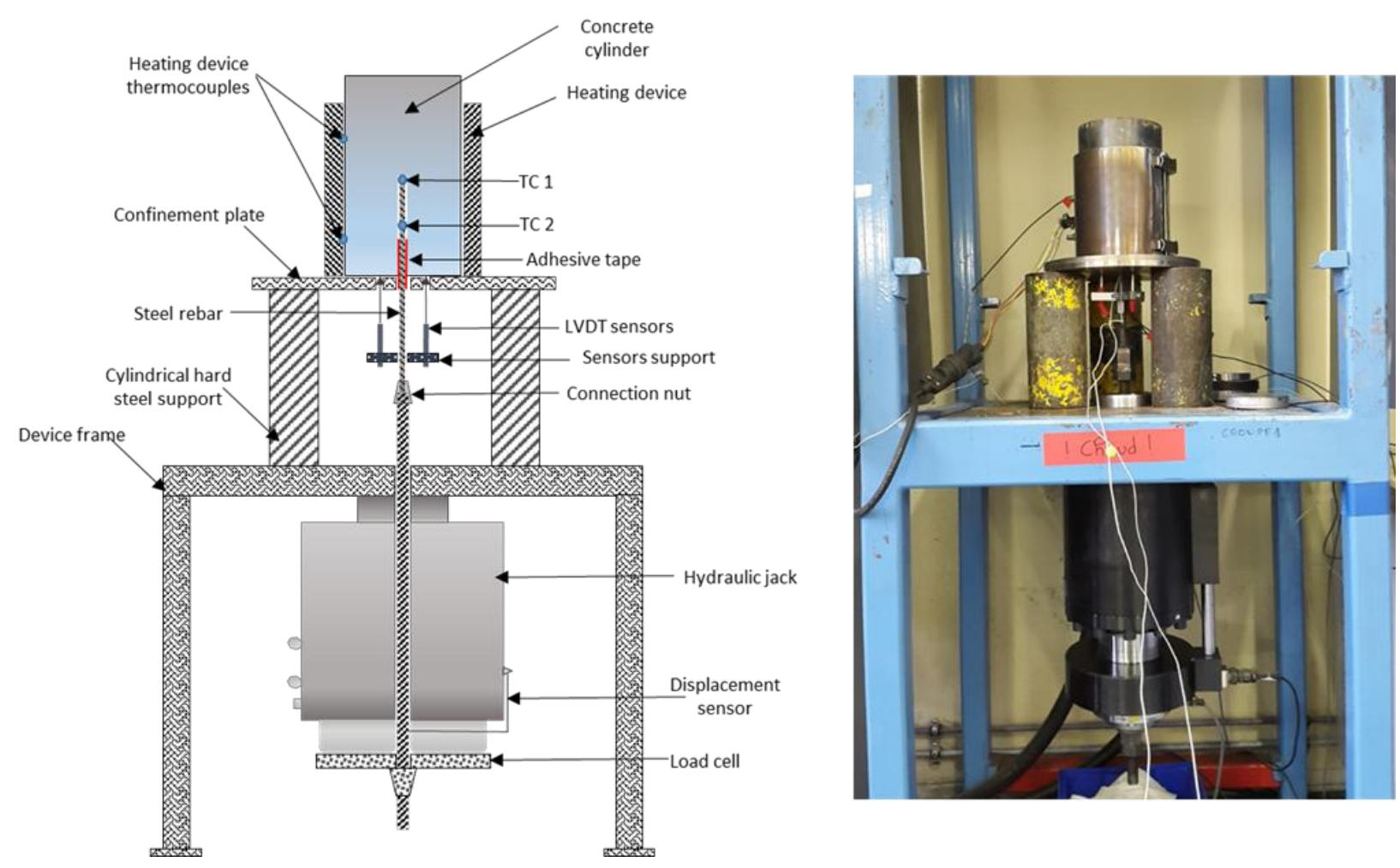

Figure 7: Pull-out experimental device

\subsection{Heating device}

The concrete cylinders were electrically heated by a cylindrical heating device controlled by a PID controller (Proportional-Integral-Derivative controller). Temperature at the surface of the concrete cylinder was controlled by two thermocouples placed between the lateral surface of the concrete specimen and the heating device. Heating rates applied for pull-out test campaigns varied between $4^{\circ} \mathrm{C} / \mathrm{min}$ and $13^{\circ} \mathrm{C} / \mathrm{min}$.

\subsection{Acquisition and control}

The control of the jack was performed using a PID controller that also recorded load and jack displacement. The acquisition of the heating device temperature, the anchor temperature, the rebar displacement and the applied load were performed every second for pull-out tests at stabilized temperature. This acquisition frequency gave the precise load values reached when failure occurred.

However, for pull-out tests at constant load, acquisition frequency was set at one recording every 5 seconds because of the test long duration. This acquisition frequency was sufficient to determine the average temperature of the anchor when failure occurred.

\subsection{Shear stress}

The design of chemical anchors at high temperature is based on determining the bond strength value. In previous experimental work [28], it has been demonstrated, by means of strain gauges installed along the anchor, that the shear stress distribution follows an exponential law when the embedment length is equal to 10 times the diameter of the anchor. Strain gauges have shown also that for these embedment lengths, the bottom of the anchor is very weakly stressed.

Indeed, previous studies have shown that there is a critical embedment length value $\left(l_{\underline{c r}}\right)$ from which the majority of the load applied to the anchor is transferred to the surrounding material by shear stresses 
[29]. Usually, the embedment length is chosen equal to 10 times the anchor diameter, which is generally greater than $1_{\text {cr_ }}[30]$. In fact, it has been demonstrated that the increase of the anchorage depth beyond the critical value $\left(l_{\mathrm{cr}}\right)$ does not induce any modification on the distribution profile of shear stresses [31]. The exact value of the critical embedment length $1_{\text {cr }}$ could be obtained by a shear-lag analytical model [29]_[32].

However, for small embedment lengths, strain gauges showed that all the anchor presents the same level of shear stress. It was reported in [10] that for small embedment lengths $(<75 \mathrm{~mm}$ for $10 \mathrm{~mm}$ diameter steel rebar), the shear stress distribution can be considered as uniform. This assumption was confirmed in [6], where it was observed that for a constant steel rebar diameter, the maximum tensile load varies linearly with the embedment length. Thus, for small embedment lengths, the shear stress value can be calculated directly from the tensile load applied to the steel rebar according to equation (4) by assuming a uniform shear stress distribution along the anchor.

$$
\tau=\frac{F}{\pi \cdot d \cdot L}
$$

Where,

- $\tau$ is the shear stress [MPa]

- $F$ is the applied load [N]

- $d$ is the diameter of the steel rebar [mm]

- $L$ is the embedment length of the steel rebar [mm]

The shear stress expression (4) will be used further in this paper to establish the relationship between the bond resistance and the bond failure temperature.

\section{Results and discussion}

\subsection{Temperature effects on bond resistance}

In order to assess the temperature effects on the bond resistance, a test program was established for the two test procedures presented in the Paragraph 2.3. The test program is given in Table 2 and Table 3. These tests tend to establish a relationship between the bond resistance and the anchor temperature.

\begin{tabular}{ccc}
\hline TEST & EMBEDMENT & BOND \\
PROCEDURE & LENGTH $[\mathrm{mm}]$ & TEMPERATURE $\left[{ }^{\circ} \mathrm{C}\right]$ \\
\hline
\end{tabular}

\begin{tabular}{|c|c|c|}
\hline \multirow{15}{*}{ 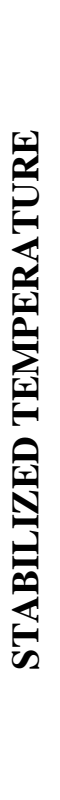 } & 60 & 16 \\
\hline & 40 & 21 \\
\hline & 40 & 25 \\
\hline & 40 & 26 \\
\hline & 40 & 38 \\
\hline & 60 & 39 \\
\hline & 60 & 40 \\
\hline & 40 & 45 \\
\hline & 40 & 50 \\
\hline & 60 & 58 \\
\hline & 60 & 61 \\
\hline & 60 & 66 \\
\hline & 60 & 70 \\
\hline & 60 & 73 \\
\hline & 60 & 80 \\
\hline
\end{tabular}




\begin{tabular}{cc}
60 & 88 \\
60 & 91 \\
60 & 101 \\
60 & 103 \\
60 & 107 \\
60 & 113 \\
\hline Table 2: Test program for pull-out tests at stabilized temperature
\end{tabular}

\begin{tabular}{|c|c|c|c|}
\hline $\begin{array}{c}\text { TEST } \\
\text { PROCEDURE }\end{array}$ & $\begin{array}{l}\text { EMBEDMENT } \\
\text { LENGTH }[\mathrm{mm}]\end{array}$ & $\begin{array}{l}\text { APPLIED } \\
\text { LOAD [kN] }\end{array}$ & $\begin{array}{c}\text { BOND STRESS } \\
{[\mathrm{MPa}]}\end{array}$ \\
\hline \multirow{10}{*}{ 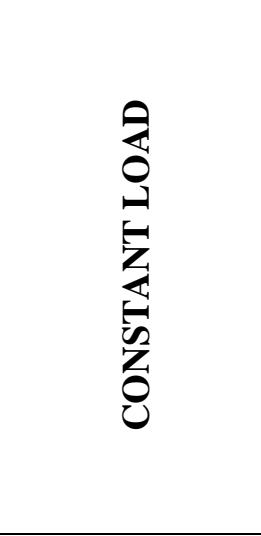 } & 40 & 41.27 & 27 \\
\hline & 40 & 38.39 & 25 \\
\hline & 60 & 46.07 & 20 \\
\hline & 60 & 45.31 & 20 \\
\hline & 60 & 35.91 & 16 \\
\hline & 60 & 27.48 & 12 \\
\hline & 60 & 23.27 & 10 \\
\hline & 60 & 17.47 & 8 \\
\hline & 60 & 12.68 & 6 \\
\hline & 60 & 6.96 & 3 \\
\hline
\end{tabular}

Two different embedment lengths were used in this two test programs. In most cases, weak embedment lengths were used for pull-out tests at low temperatures in order to avoid steel yielding.

\subsubsection{Pull-out tests at stabilized temperature}

The objective of this test procedure was to establish a relationship between the bond resistance and the temperature of the anchor. This relationship can be used further in the design of chemical anchors in fire situation.

Figure 8 shows the results obtained from pull-out tests at stabilized temperature. The bond resistance was directly calculated from the maximum tensile load reached during tests using equation (4).

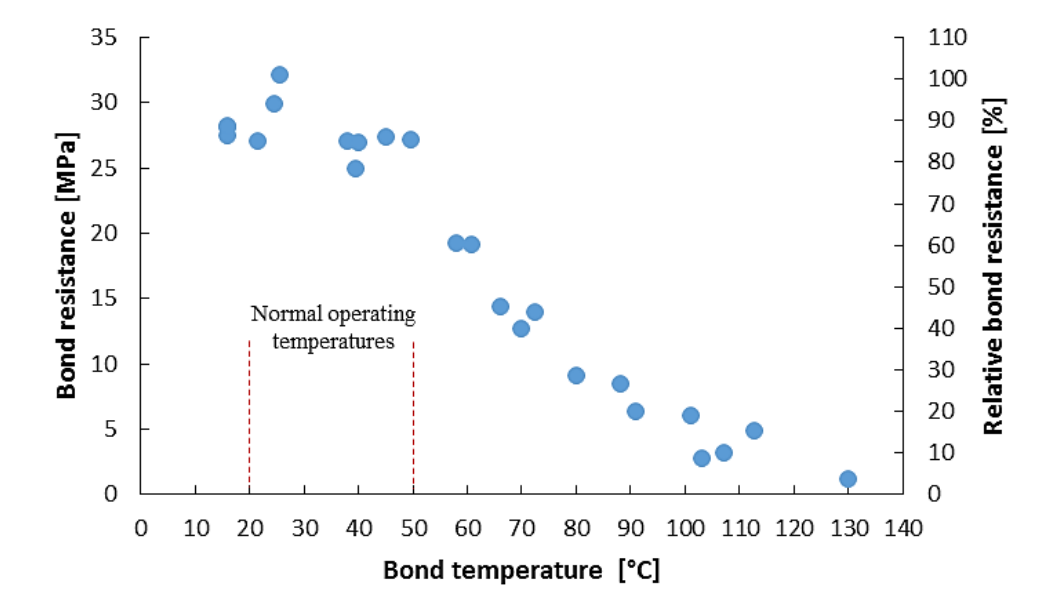

Figure 8: Bond resistance and Relative bond resistance vs Bond temperature for pull-out tests at stabilized temperature 
Results obtained from tests showed an almost constant bond resistance for temperatures comprised between $20^{\circ} \mathrm{C}$ and $50^{\circ} \mathrm{C}$, with a slight increase at $24^{\circ} \mathrm{C}$ and $26^{\circ} \mathrm{C}$. This results confirm that epoxy resins provide constant mechanical performances at normal operating conditions, as mentioned in [17]. The slight increase in bond resistance at $24^{\circ} \mathrm{C}$ and $26^{\circ} \mathrm{C}$ could be attributed to the resin post-cure phenomenon. In fact, exposing polymers to heat over time leads to increase the degree of cross-linking of the chemical reaction between the resin and the hardener, as explained in Section 2.2.2. The increase of the cross-linking degree tends consequently to improve the mechanical performances of the polymer. This post-cure effect was not observed on specimens at $16^{\circ} \mathrm{C}$ and $21^{\circ} \mathrm{C}$ as they were tested at ambient temperature and did not receive any thermal conditioning.

Beyond $50^{\circ} \mathrm{C}$, the resin lost about $30 \%$ of its bond strength. Starting from this temperature, the curve decreases with a convex trend. The pull-out tests showed that when the anchor temperature reached $130^{\circ} \mathrm{C}$, the resin had lost around $96 \%$ of its initial bond resistance. This resistance drop, observed starting from $50^{\circ} \mathrm{C}$, can be attributed to physical and chemical phenomena that occur in the resin at high temperature.

\subsubsection{Pull-out tests at constant load}

The main goal of this test procedure was to associate a failure bond temperature to different values of shear stress applied on the adhesive joint. Obtained results can be injected further in finite element codes to model the mechanical behavior of chemical anchors in fire situation. In addition, this test procedure is very interesting to study because it reproduces the real manner in which behaves chemical anchors in a structure subjected to fire, and may reveal the presence of interesting phenomena such as creep. Creep is a mechanical phenomenon defined as an irreversible deformation of the material under a constant load. Therefore, creep is responsible for the material yielding and leads to the deterioration of its mechanical properties.

The heating rate was identical for all pull-out tests at constant load. The applied load values were chosen in order to apply a quantity of 3, 6, 8,10,12,16,20, 25 and $27 \mathrm{MPa}$ of bond stress in the adhesive joint, calculated using equation (4).

Results obtained from pull-out tests at constant load are shown in Figure 9.

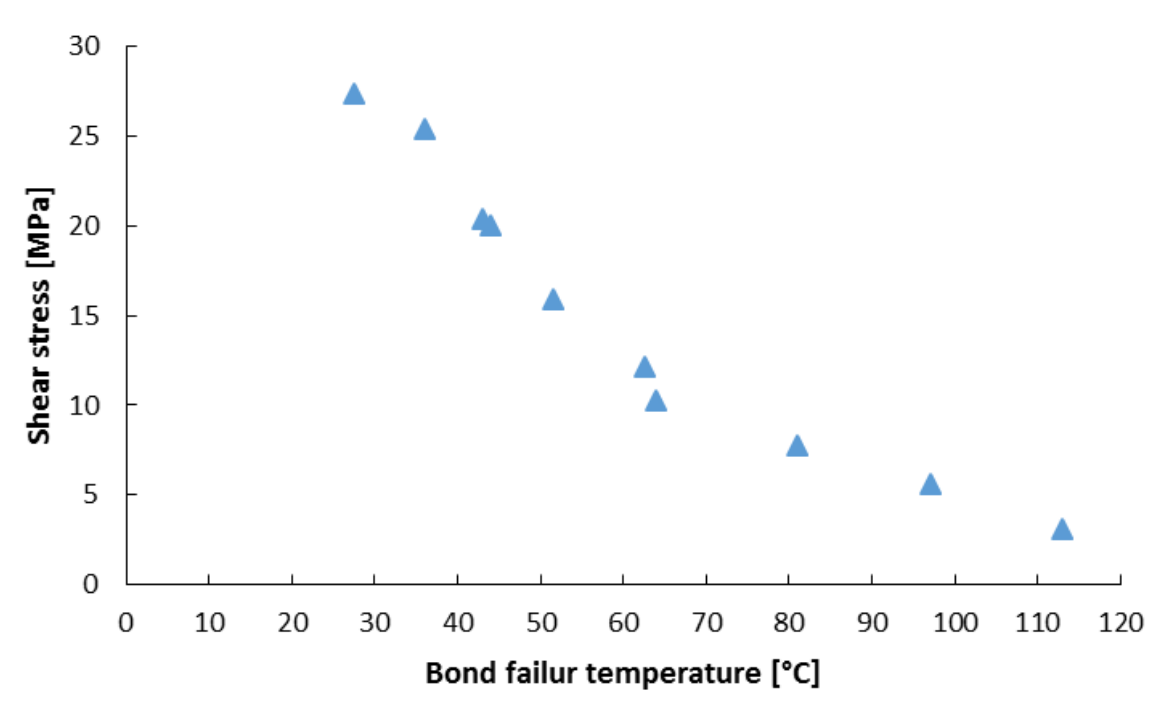

Figure 9: Bond stress vs bond failure temperature curve for pull-out tests at constant load 
Results show that for this epoxy resin, the bond failure occurs at $27^{\circ} \mathrm{C}$ for a quantity of $27 \mathrm{MPa}$ bond stress, which is lower than the temperature obtained in the previous test campaign (pull-out tests at stabilized temperature). Failure temperature increases by decreasing the applied bond stress $\left(115^{\circ} \mathrm{C}\right.$ for $3 \mathrm{MPa}$ ). Test results showed also that the chemical anchor had lost more than $65 \%$ of its initial bond resistance when bond temperature reached $63^{\circ} \mathrm{C}$.

The tests carried out highlighted the presence of a thermal gradient between the top and the bottom of the embedded part, recorded by TC1 and TC2 (Figure 2), when heating the concrete cylinder. The presence of a thermal gradient between the two ends of the anchor have naturally a strong effect on the stress distribution along the adhesive joint and therefore affects the fire resistance of the chemical anchor. Indeed, in addition to the small heat loss generated by the contact between the concrete surface and the confinement plate, the thermal gradient comes essentially from hydro-thermal phenomena when heating concrete, such as vaporization and water migration towards the center of the test specimen [4].

\subsubsection{Results comparison between the two test procedures}

Comparison of results from the two different test procedures puts into light 3 observations:

1- Similar bond resistances were obtained from the two pull-out test procedures for temperatures below $36^{\circ} \mathrm{C}$. These close results could be explained by the weak effect of resin post-cure and creep phenomena at low temperatures. Indeed, the resin temperature remains close to room temperature, and therefore the impact of heat is relatively weak in accelerating the polymerization reaction and in increasing the resin crosslinking degree, as explained in Section 2.2.2. Consequently, the effect of post-cure phenomenon in improving the bond resistance is very slightly pronounced for these temperatures. In addition, the resin creep is negligible for temperatures close to room temperature [1], thus, there is no significant bond strength degradation due to creep at low temperatures.

2- For bond temperatures between $36^{\circ} \mathrm{C}$ and $80^{\circ} \mathrm{C}$, the superposition of pull-out curves (Figure 10) reveals an important gap between results from the two test procedures, especially at $50^{\circ} \mathrm{C}$. In fact, bond resistance at stabilized temperature is higher than bond resistance at constant load. This significant difference could be a consequence of thermal, chemical and mechanical phenomena that may occur in a loaded and heated adhesive joint, such as post-cure, creep and water migration.

In fact, during pull-out tests at stabilized temperature, the resin temperature remains high and constant for at least two hours, according to the test procedure. The increase in resin temperature activates the post-cure phenomenon by supplying more energy and flexibility to epoxy molecules to react with the hardener and to form a more developed molecular network. Furthermore, the exposure to high temperatures for a long period evaporates the free water contained in the resin and thus creates an additional empty volume facilitating and accelerating the crosslinking between epoxy molecules, leading consequently to increase the bond resistance. On the other side, this gap is possibly accentuated by the resin creep phenomenon which may appear during pull-out tests at constant load and causes a decrease in the mechanical properties of the adhesive joint.

However, above $60^{\circ} \mathrm{C}$, the gap decreases progressively when increasing the bond temperature. These results may be explained by two chemical phenomena:

- The achievement of the resin post-cure: The polymerization reaction reaches its maximum crosslinking degree and therefore the heating of the resin does no longer contribute in improving the bond resistance. DSC tests showed that post-cure ends at a temperature less than or equal to $82^{\circ} \mathrm{C}$ (Figure 6).

- The resin glass transition: The change in the resin physical state due to heat acts negatively on the adhesive mechanical properties by decreasing its stiffness and its strength capacity. The glass transition temperature of the epoxy resin used in pull-out tests was determined by DSC tests and was around $62^{\circ} \mathrm{C}$ (Figure 5). 
This two phenomena reacting together may explain the gradual narrowing gap between the two test campaign results when bond temperature exceeds $60^{\circ} \mathrm{C}$.

3- For bond temperature higher than $80^{\circ} \mathrm{C}$, results from the two test procedures meet again and the gap disappears progressively. This observation could be related to phenomena already mentioned such as the achievement of the post-cure with the end of the bond strengthening by supplying heat, the resin glass transition accompanied by the decay in the bond resistance, and finally the instantaneous creep.

Instantaneous creep is directly related to the resin glass transition which transforms the mechanical behavior of the resin from elastic to viscoelastic. This change in mechanical properties leads to an identical bond reaction to instantaneous or long-term loading. Therefore, the resin's creep becomes independent of the applied load duration and hence, the mechanical response of the bond becomes the same for both test procedures.

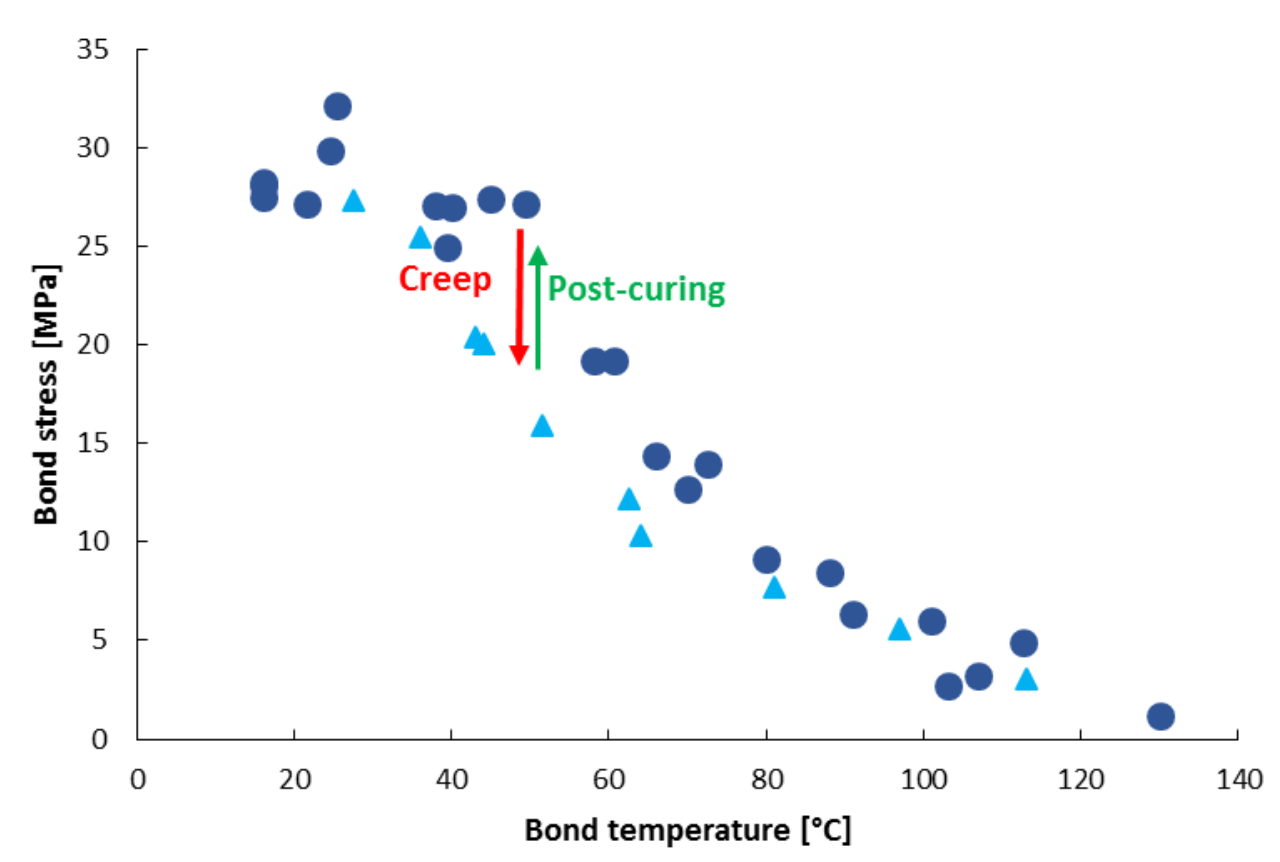

$\Delta$ Constant load $\quad$ Stabilized temperature

Figure 10: Results superposition from the two pull-out test procedures

\subsection{Temperature effects on the anchor stiffness}

Through the measurement of rebar displacements during pull-out tests at stabilized temperature, it was possible to study the evolution of the mechanical properties of chemical anchors at different temperatures. Curves in Figure 12 show the variation of the bond stress vs the rebar slip for chemical anchors tested at the chosen target temperatures. The bond stress was calculated from the tensile force applied to the rebar, by knowing the embedment length and using equation (4). The rebar slip is the relative displacement between the concrete surface and the steel rebar at the beginning of the anchor (relative displacement between point 1 and point 2 in Figure 11), and was calculated using equations (5) and (6). For technical reasons, it was not possible to install the LVDT sensors exactly at the beginning of the anchor. Therefore, LVDTs were positioned at a distance $\mathrm{L}_{0}$ from the concrete surface (Figure 11). The rebar slip was then calculated from the displacement measured by the LVDTs, by subtracting the elastic elongation of the rebar along $\mathrm{L}_{0}$, as described in equation (5). 


$$
\begin{gathered}
\delta=\Delta L_{L V D T}-\Delta L_{e} \\
\Delta L_{e}=\frac{F L_{0}}{E S}
\end{gathered}
$$

Where,

- $\quad \delta$ is the rebar slip

- $\quad \Delta L_{L V D T}$ is the mean displacement measured by the three LVDT sensors

- $\quad \Delta L_{e}$ is the elastic elongation of the free unbounded part of the steel rebar

- $\quad E$ is the Young's modulus of the steel rebar obtained by tensile tests (Figure 1)

- $\quad F$ is the applied tensile load

- $\quad S$ is the cross section of the steel rebar

- $\quad L_{0}$ is the free distance between the top of the anchor and the LVDTs' support (Figure 11)

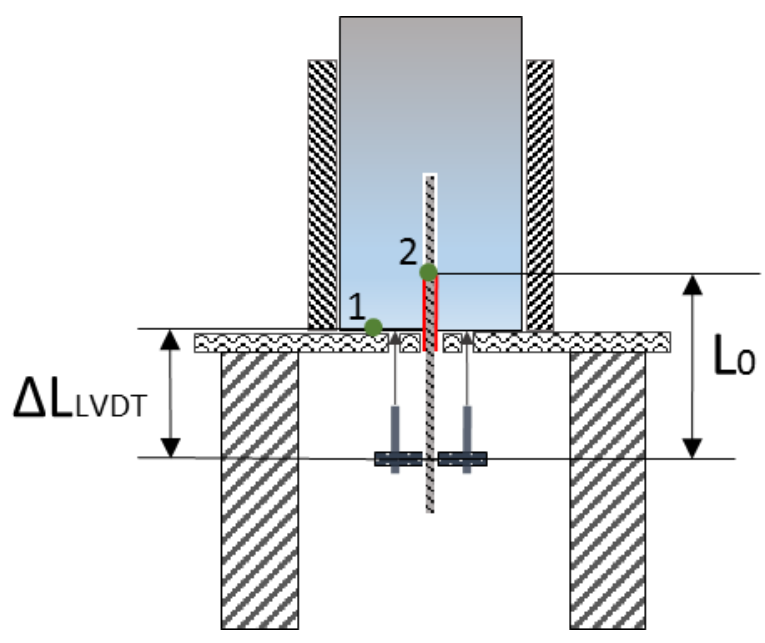

Figure 11: Distances considered in slip measurements


Figure 12: Bond stress vs rebar slip for stabilized temperatures at different ranges a) Target temperatures between $20^{\circ} \mathrm{C}$ and $50^{\circ} \mathrm{C}, \mathrm{b}$ ) Target temperatures between $50^{\circ} \mathrm{C}$ and $105^{\circ} \mathrm{C}$, c) Target temperatures higher than $105^{\circ} \mathrm{C}$ 
Bond stress vs rebar slip curves (Figure 12) confirm the change in mechanical response of chemical anchors under temperature effect. Indeed, results show that anchor stiffness and bond resistance decrease when temperature increases. Observations highlighted that the anchor mechanical response varies with the temperature to which the anchor is exposed. For this reason, curves in Figure 12 were divided into three groups depending on the sensitivity of the anchor mechanical response to temperature.

- Group 1: Pull-out tests performed at temperatures between $20^{\circ} \mathrm{C}$ and $50^{\circ} \mathrm{C}$ (Figure 12.a).

At this temperature range, the anchor stiffness and the bond resistance remain constant and independent on bond temperature. This observation confirms that epoxy resins show a constant mechanical behavior at normal operating temperatures, as mentioned in [17].

Load / unload pull-out tests were carried out on chemical anchors at ambient temperature and allowed to detect the presence of four mechanical zones on each of curves belonging to this first group.

- Zone 1: A linear portion along which the bond stress increases linearly with the slipping of the steel rebar. In this zone, the anchor shows the same stiffness up to a certain bond stress value. This means that the adhesive joint deforms elastically and therefore deformations are reversible, which means that no damage or cracking occurs in the adhesive bond (Figure 13.a).

- Zone 2: A nonlinear portion: Adhesive bond yielding and crack initiation. (Figure 13.b). For high bond stress values (around $22 \mathrm{MPa}$ ), the rebar slip becomes important and increases nonlinearly with the applied bond stress. Removing the tensile load applied on the steel rebar does not allow to reach the initial slipping values any more, as shown in Figure 13.b. These observations indicate that the adhesive joint is yielded and the bond deforms irreversibly. At this stage, cracks appear in the adhesive joint and dissipate the energy induced by shear forces. Crack formation is highlighted by the progressive decrease in the anchor stiffness shown by the change in the slope of the straight lines in Figure 13.b between cycles 4 and 6 . At the end of this step, the bond stress reaches its maximum value (bond resistance) and stop increasing.

- Zone 3: A third portion of damage propagation and bond failure (Figure 13.c). The cracks formation and propagation continue under the tensile force effect until total bond failure. When the total bond failure occurs, the bond stress decreases and the rebar starts to rip out. The rebar slip recorded in this portion is therefore quite important (around $6 \mathrm{~mm}$ for the tested specimen presented in Figure 13.c).

- Zone 4: Rebar slipping and frictional resistance zone (Figure 13.d). The adhesive bond is now completely damaged. The rebar extraction continues under the tensile load effect and the shear stress value remains almost constant until the total extraction of the steel rebar. The shear stress, which continues to exist despite the bond failure, may be explained by the frictional forces created by the contact between the failed adhesive joint and the concrete surface. 

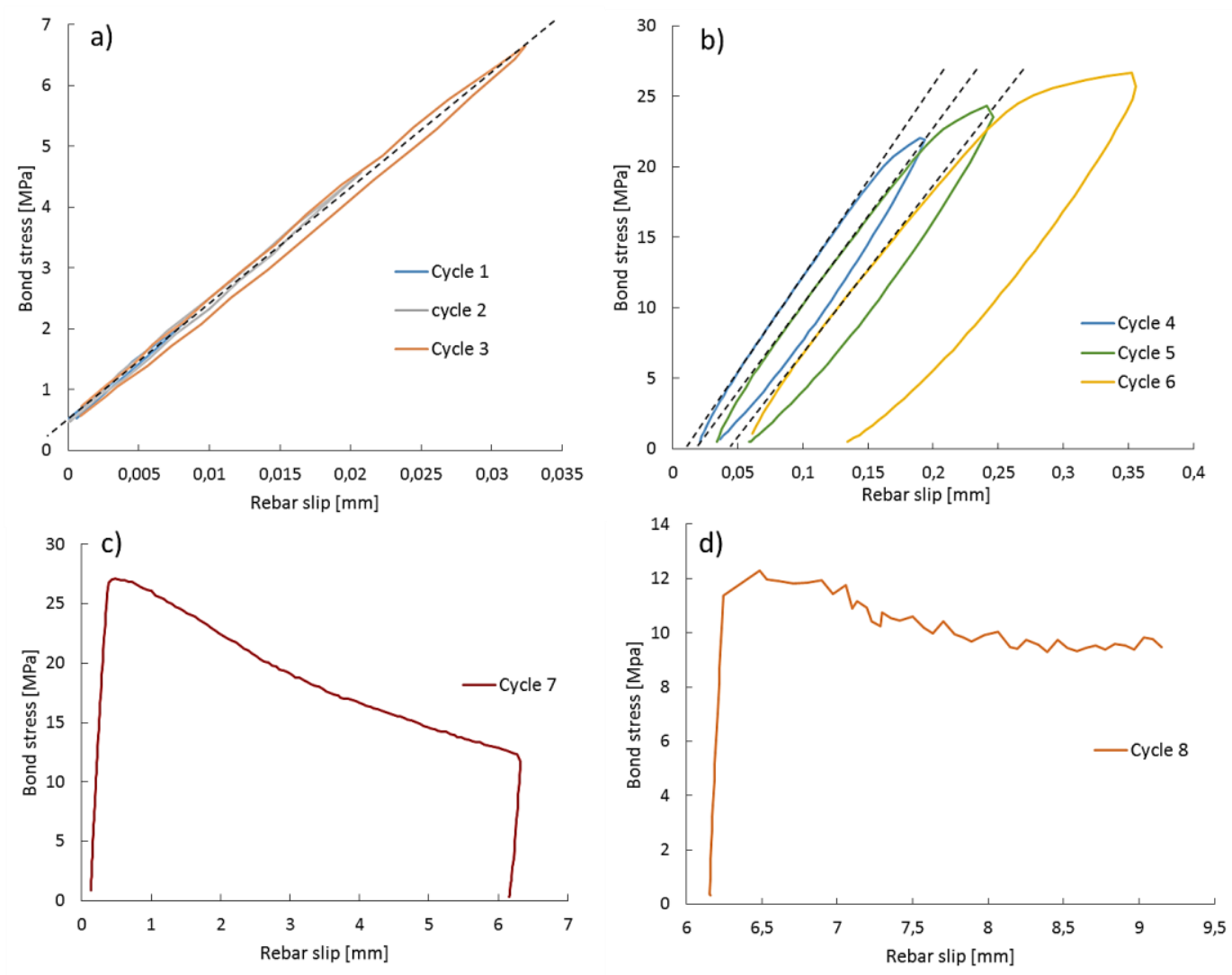

Figure 13: The four mechanical zones of a chemical anchor loaded at a temperature lower between $20^{\circ} \mathrm{C}$ and $50^{\circ} \mathrm{C}$ a) Elastic zone, b) yielding and crack initiation zone, c) damage propagation and bond failure zone, d) Slipping and frictional resistance zone

- Group 2: Pull-out tests performed at temperatures between $50^{\circ} \mathrm{C}$ and $105^{\circ} \mathrm{C}$.

For these temperatures, the mechanical behavior of chemical anchors becomes highly dependent on temperature, and the resin becomes more and more viscoelastic as the anchor temperature exceeds the resin glass transition temperature (Section 2.2.2). The more the temperature increases, the more the mechanical properties of chemical anchors decrease (Figure 12.b). At high temperatures (near to $100^{\circ} \mathrm{C}$ ), it becomes difficult to distinguish the four mechanical zones described in group 1 . The change in the mechanical behavior of chemical anchors under high temperature effect induced a change in the failure mode (Section 3.3).

- Group 3: Pull out tests performed at temperatures higher than $105^{\circ} \mathrm{C}$.

Under high temperature effect, the resin melts and loses its resistance properties. Consequently, the anchor resists very weakly to pull-out forces. The different mechanical behavior zones observed on the previous curves disappear and leave its place to a single zone (Figure 12.c). The anchor resists to pullout forces only by friction with concrete surface. So it can be said that, at this temperature range, the resin is unable to provide mechanical strength to the anchor.

\subsection{Temperature influence on failure modes}

Pull-out tests revealed the existence of three possible failure modes, depending on the anchor temperature:

- Steel rebar/resin interface (cohesive failure mode)

- Resin/concrete interface (adhesive failure mode) 
- Mixed failure mode

The steel rebar/resin interface failure mode was observed for low bond temperatures (lower than $50^{\circ} \mathrm{C}$ ). As shown in Figure 14.a, this failure mode is characterized by the debonding of the resin from the surface of the steel rebar and reflects the high resistance of the adhesive bond to pull-out forces until its failure. This failure mode can be explained by the brittle elastic behavior of the epoxy resin at low temperatures [1], which leads to the cracking of the adhesive joint under shear stresses.

Mixed failure mode (adhesive and cohesive mode) was observed along the embedment length for pullout tests performed at temperatures comprised between $50^{\circ} \mathrm{C}$ and $75^{\circ} \mathrm{C}$. This mixed failure mode appeared in almost cases when performing pull out-tests at constant load due to the presence of a thermal gradient along the anchor. Indeed, this failure mode is characterized by a resin/concrete interface failure at the top of the anchor (the hottest part), and by a steel/resin interface failure in the bottom of the anchor (at the coldest part) as shown in Figure 14.b. In fact, when heating the test specimen, the top of the anchor is heated more quickly than the bottom due to the high thermal conductivity of the steel confinement plate, which supplies an additional heat flux to the anchor. In addition, hydro-thermal phenomena that occur at the center of the test specimen during heating slow down the temperature increase at the bottom of the anchor, as described is Paragraph 3.1.2. Consequently a thermal gradient appears along the anchor and therefore, the top of the anchor reaches firstly the glass transition temperature, the resin melts and the failure occurs at the adhesive bond. However, the temperature at the bottom of the anchor remains below the resin glass transition temperature, and consequently, at the bottom of the anchor, the resin maintains its mechanical properties and resists to the shear stress, and thus failure occurs at the steel/resin interface.

Above $75^{\circ} \mathrm{C}$, only resin/concrete interface failure mode was observed. This failure mode can be explained by the total glass transition of the resin and its physical state change from solid to vitreous state, since the anchor temperature exceeds the resin glass transition temperature (Paragraph 2.2.2). At this temperature range, the resin present a very low mechanical properties and resists weakly to the applied tensile force. Consequently, pull-out tests lead to the total extraction of the adhesive joint as shown in Figure 14.c.

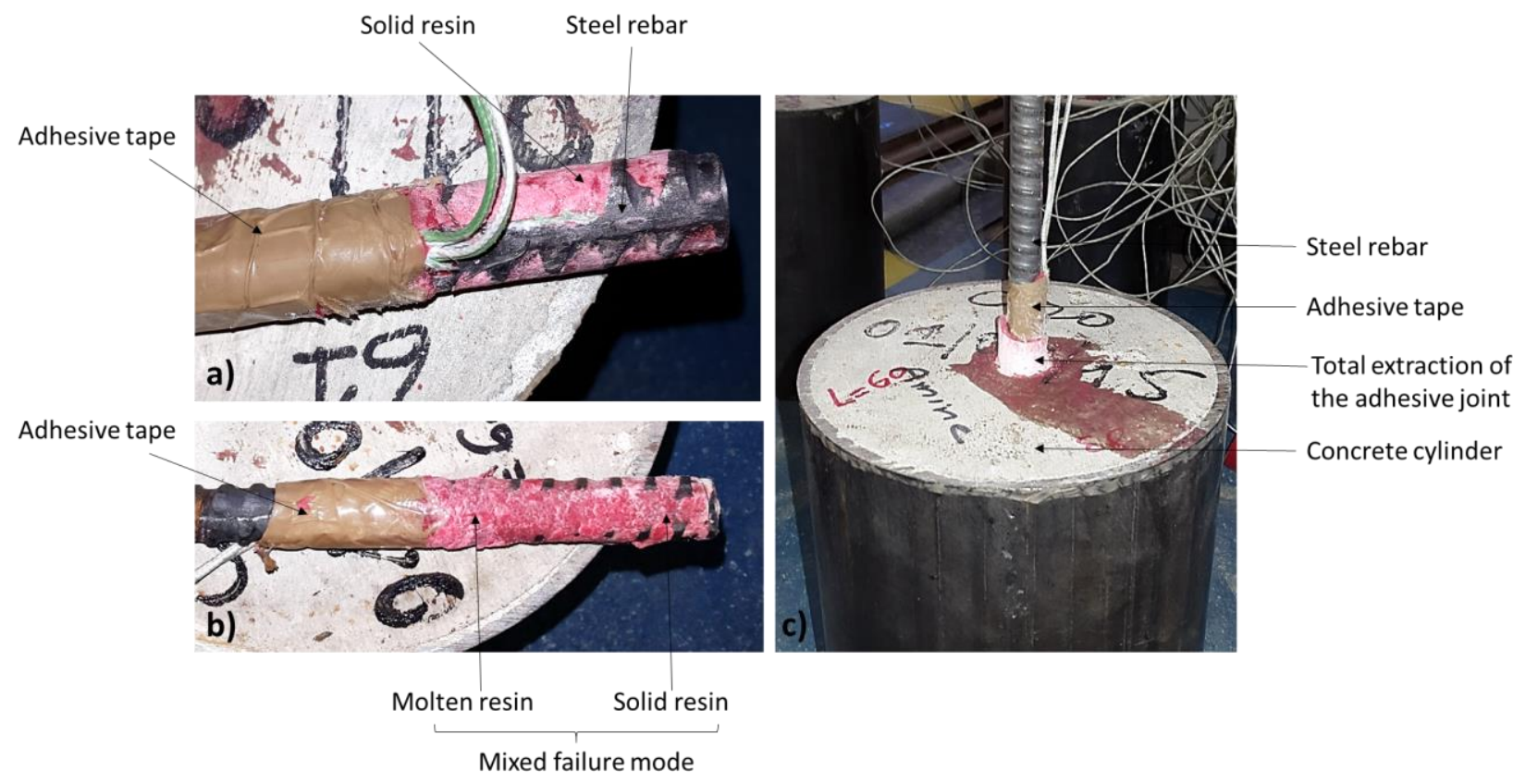

Figure 14: Examples of different failure modes observed during pull-out tests. a) Steel rebar/resin interface $\left(21^{\circ} \mathrm{C}\right)$, b) Mixed failure mode $\left.\left(65^{\circ} \mathrm{C}\right), \mathrm{c}\right)$ Resin/concrete interface $\left(100^{\circ} \mathrm{C}\right)$ 


\subsection{Incompatibility of anchor displacements in the current design method}

The current method used for the design of chemical anchors in fire situation [25] is based on two steps.

The first step consists in the determination of the temperature distribution along the anchor at different moments of fire exposure, using thermal calculations. Thermal calculations can be done either by finite element analysis, or by analytical calculations using finite difference method based on Fourier equations (7), (8) and (9). These two calculation methods require the knowledge of the variation of the thermal properties of the materials composing the chemical anchor depending on temperature $(\lambda(\theta)$, $\mathrm{C}_{\mathrm{p}}(\theta)$ and $\left.\rho(\theta)\right)$.

$$
\begin{aligned}
\rho(\theta) \cdot C_{p}(\theta) \cdot \frac{\partial \theta}{\partial t} & =\lambda(\theta) \cdot \frac{\partial^{2} \theta}{\partial x^{2}}+\dot{q}_{\text {con }}+\dot{q}_{\text {ray }} \\
\dot{q}_{\text {con }} & =h \cdot\left(\theta_{\text {ext }}-\theta_{\text {sur }}\right) \\
\dot{q}_{\text {ray }} & =\sigma \cdot \varepsilon \cdot\left(\theta_{\text {ext }}^{4}-\theta_{\text {sur }}^{4}\right)
\end{aligned}
$$

Where,

- $\quad \rho$ is the material density $\left[\mathrm{kg} / \mathrm{m}^{3}\right]$

- $\quad C_{p}$ is the material specific heat $\left[J . K^{-1} . K^{-1}\right]$

- $\quad \lambda$ is the material conductivity $\left[W . m^{-1} . K^{-1}\right]$

- $\quad \theta$ is the temperature of an element of the anchor at position $x$ and at time $t[K]$

- $\quad \dot{q}_{c o n}$ is the convective heat flux per unit area $\left[W \cdot m^{-2}\right]$

- $\quad h$ is the heat transfer coefficient $\left[W \cdot m^{-2} \cdot K^{-1}\right]$

- $\quad \dot{q}_{\text {ray }}$ is the radiative heat transfer per unit area $\left[W \cdot m^{-2}\right]$

- $\sigma$ is the Stefan-Boltzmann constant $\left[W . m^{-2} K^{-4}\right]$

- $\quad \varepsilon$ is the emissivity of the material

- $\theta_{\text {ext }}$ is the exposure temperature [K]

- $\quad \theta_{\text {sur }}$ is the temperature at the surface of the material [K]

At the end of this first step, a temperature map is obtained, allowing the knowledge of the exact temperature values on every element of the anchor and at different moments of fire exposure.

The second step consists in associating a bond resistance value to each element of the anchor using previous thermal calculation results and using the relationship between the bond resistance and the anchor temperature obtained by pull-out tests (Figure 10). The anchor's load bearing capacity at time $t$ is therefore obtained by summing the bond resistances along the entire embedment length following equation (10), as described in the example in Figure 15.

$$
F_{t}=2 \pi r \int_{0}^{L} \tau_{\max }(\theta(x, t)) d x
$$

Where,

- $\quad F_{t}$ is the load bearing capacity of the anchor at time $t[N]$

- $\quad r$ is the radius of the steel rebar [mm]

- $\quad L$ is the embedment length [mm]

- $\tau_{\text {max }}$ is the bond resistance obtained by pull-out tests [MPa]

- $\theta(x, t)$ is the temperature of the element of the anchor at position $x$ and at time $t$. 
This design method supposes that failure occurs when the anchor's load bearing capacity $F_{t}$ becomes equal to or lower than the applied tensile load.

In this design method, the calculation of the anchor's load bearing capacity is mainly based on the knowledge of the thermal distribution along the anchor and on considering the maximum shear stress to which can resist each element. It means that this method does not consider the true evolution of the shear stress distribution along the anchor during fire exposure, which can be determined either by analytical calculations using a shear-lag model [33], or by a numerical analysis using finite element modeling [22]. Nevertheless, this assumption seems to be sufficient to predict the time collapse since the failure occurs when the shear stress saturates along the anchor, i.e. when the shear stress reaches the bond resistance at all the elements of the anchor. However, by assuming that each element of the anchor provides its maximum shear stress capacity during fire exposure, all the elements of the anchor should reach their maximum shear stress capacity at the same value of relative displacement $\delta^{\prime}$, and consequently, the anchor should present an elastoplastic mechanical behavior (Figure 15.a).

The example in Figure 15.a shows an application of the design method described above. The considered chemical anchor is composed of three elements. Each element has a temperature $\theta_{i}$, different from the temperature of the two others. Knowing the temperature distribution along the anchor, a bond resistance $\tau_{\text {imax }}$ is associated to each element using results obtained from pull-out tests. The load bearing capacity of the anchor $\left(F_{t}^{1}\right)$ is therefore calculated by summing the bond resistances of the three elements composing the anchor.

Bond stress vs rebar slip curves obtained from pull-out tests at stabilized temperature are shown in Figure 16. The rebar slip was calculated according to equations (5) and (6), as described in Section 3.2. Results in Figure 16 show that in reality, the chemical anchor present a mechanical behavior totally different from the elastoplastic behavior, and that the maximum shear resistance of a chemical anchor is not reached at the same value of rebar slip for different temperatures. Thus, for a given relative displacement value $\delta_{0}$, the anchor elements do not all provide their maximum shear stress capacity (Figure 15.b). Consequently, the anchor's load bearing capacity $F_{t}^{2}$, obtained by summing the bond shear stress values for different temperatures and corresponding to a relative displacement $\delta_{0}$, is lower than that provided by the design method $\left(F_{t}^{1}\right)$. 


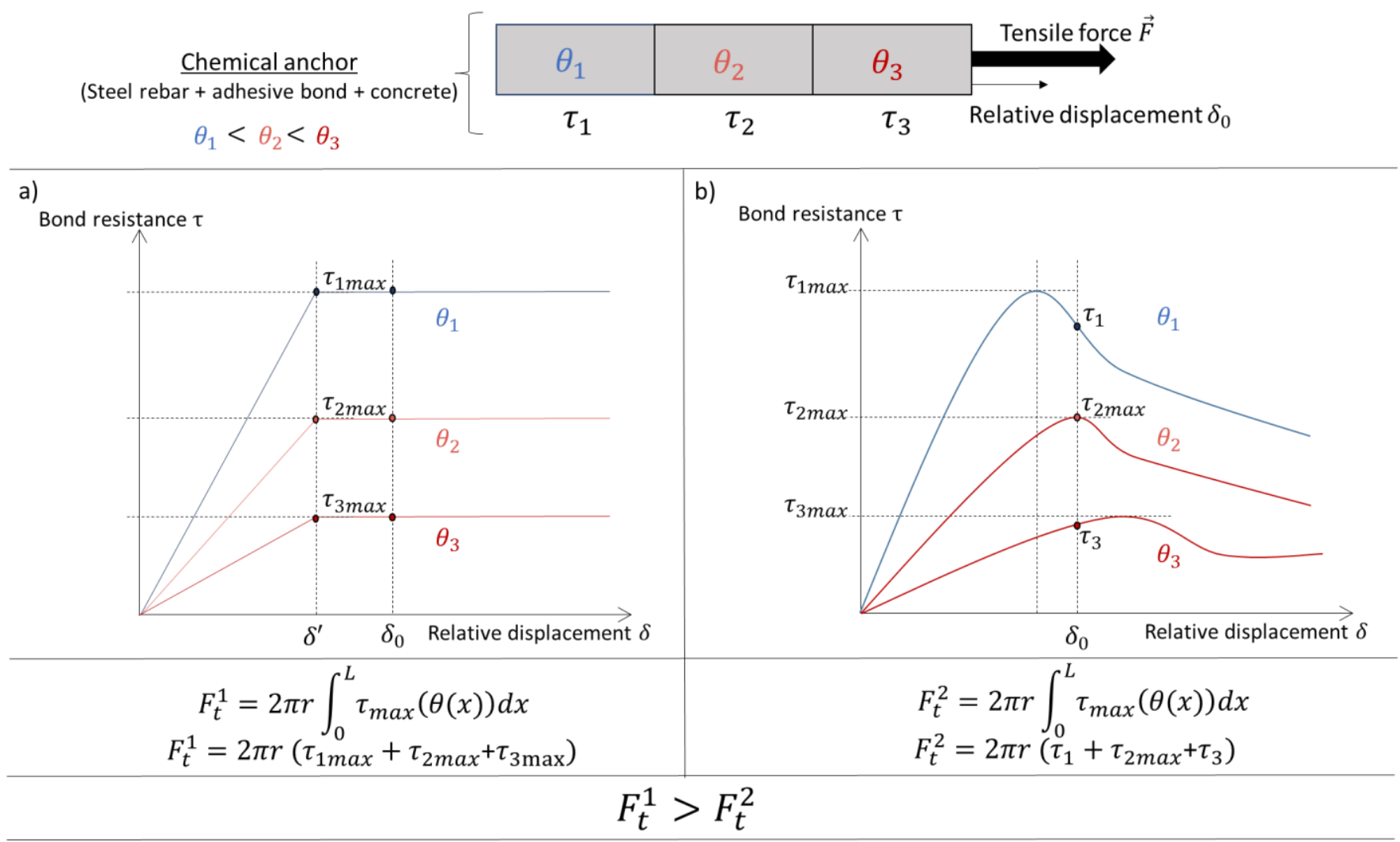

Figure 15: Example of incompatibility of displacements in the current design method a) Anchor's mechanical behavior suggested by the design method / b) Real anchor's mechanical behavior

To illustrate this point, let's consider for example a slab connected to a wall using only one chemical anchor of $16 \mathrm{~mm}$ diameter and $135 \mathrm{~mm}$ embedment length. The anchor is placed at $100 \mathrm{~mm}$ from the surface of the slab directly exposed to ISO 834-1 fire [21] and subjected to a tensile force equal to 40 $\mathrm{kN}$. The temperature evolution along the anchor is obtained by thermal calculations. Calculated temperature values are used next in calculating the evolution of the anchor's load bearing capacity during fire exposure. Table 4 presents a comparison of the evolution of the anchor's load bearing capacity at different moments of fire exposure calculated using the current design method and by considering different values of anchor slip during test.

\begin{tabular}{ccccc}
\hline $\begin{array}{c}\text { Fire } \\
\text { exposure } \\
\text { duration } \\
{[\text { min] }}\end{array}$ & $\begin{array}{c}\text { Current } \\
\text { design } \\
\text { method } \\
{[\mathbf{k N}]}\end{array}$ & $\begin{array}{c}\mathbf{2} \mathbf{~ m m} \\
\text { slip } \\
{[\mathbf{k N}]}\end{array}$ & $\begin{array}{c}\mathbf{2 . 5} \mathbf{~ m m} \\
\text { slip } \\
{[\mathbf{k N}]}\end{array}$ & $\begin{array}{c}\mathbf{3} \mathbf{~ m m} \\
\text { slip } \\
{[\mathbf{k N}]}\end{array}$ \\
\hline 0 & 191 & 175 & 149 & 139 \\
30 & 191 & 175 & 149 & 139 \\
60 & 183 & 172 & 148 & 128 \\
90 & 114 & 104 & 92 & 77 \\
120 & 54 & 40 & 38 & 37 \\
\hline
\end{tabular}

Table 4: Comparison of the anchor's load bearing capacity values obtained using the current design method and by integrating the anchor slip criterion

As results show in Table 4, the current design method suggests that after 120 minutes of fire exposure, the anchor still able to resist to an amount of pull-out force equal to $54 \mathrm{kN}$, which means that the load bearing capacity of the anchor still greater than the applied tensile load. Therefore, the actual design 
methods predicts that the anchor is able to resist to an ISO fire exposure for at least more than two hours. However, when taking into account the post-peak behavior of the pull-out curves by considering a value of $2 \mathrm{~mm}$ anchor slip, calculations show an important decay in the anchor's load bearing capacity up to $40 \mathrm{kN}$. Therefore, for this anchor slip value, the anchor's load bearing capacity after two hours of ISO fire exposure has become equal to the applied tensile load. Thus, the anchor failure should occur exactly after two hours of fire exposure.

Additional calculations made considering $2.5 \mathrm{~mm}$ and $3 \mathrm{~mm}$ anchor slip values showed that the anchor's load bearing capacity decreases by increasing the slip value for the same fire exposure duration. Therefore, for these anchor slip values, calculations show that the anchor is not able anymore to resist to two hours of ISO fire exposure.

In conclusion, the current design method overestimates the fire resistance of chemical anchors by supposing that each element of the anchor provides its maximum shear stress capacity when failure occurs and by not taking into account the pre and post peak behavior of pull-out curves. Consequently, this design method is not conservative and cannot ensure a safe use of chemical anchors in fire situation. It is therefore necessary to consider a displacement criterion and to use bond shear vs rebar slip curves at different temperatures to design the fire resistance of chemical anchors instead of considering only the relationship between the bond resistance and the anchor temperature.

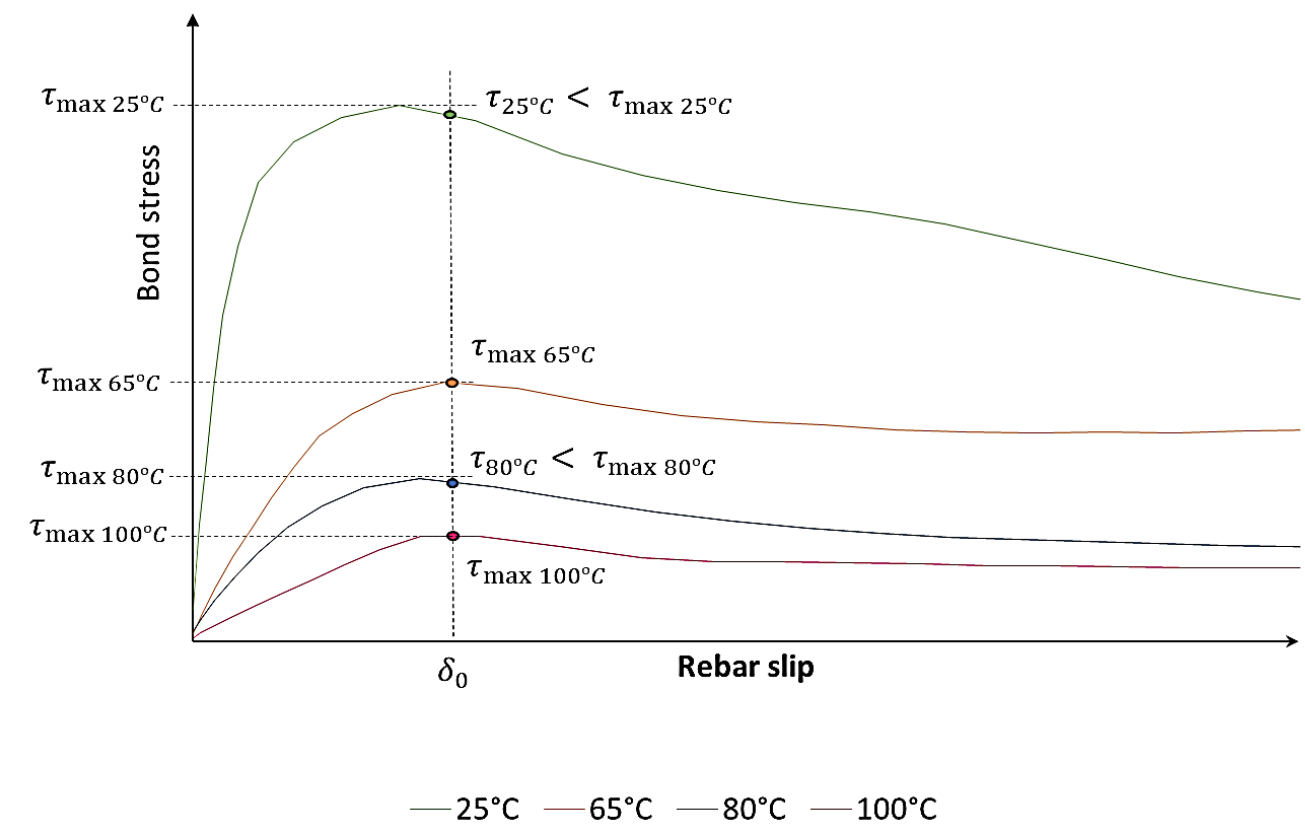

Figure 66: Bond stress vs rebar slip curves showing the real mechanical behavior of a chemical anchor at different temperatures

\section{Conclusion}

Thanks to its high mechanical properties at normal operating temperatures, bonded post-installed rebars have gradually substitute cast-in place rebars and provided new technical solutions to build sustainably and more efficiently. However, the fire resistance of chemical anchors present the weakest point of this anchoring technique.

Pull-tests at stabilized temperature and at constant load were performed in this study in order to assess the mechanical behavior of chemical anchors in fire situation. Measurements of anchor temperature, steel rebar displacement and applied tensile load were carried out on each of these tests. Measurements revealed a strong dependence of the mechanical behavior of chemical anchors on temperature. 
From this study, the following conclusions can be derived:

- Chemical anchors made with the epoxy resin used in this study present an almost constant load bearing capacity and stiffness at normal operating temperatures $\left(\theta<50^{\circ} \mathrm{C}\right)$. Beyond these temperatures, the mechanical properties of the anchor rapidly decrease.

- Results obtained from the two pull-out test procedures were very close at normal operating temperatures. Nevertheless, these results diverge at higher temperatures $\left(\theta>50^{\circ} \mathrm{C}\right)$. This divergence could be related to creep, water migration and post-cure phenomena. At temperatures higher than $80^{\circ} \mathrm{C}$, results meet again and bond resistance continues decreasing when heating.

- The heating of the chemical anchor until a given temperature leads to improve its mechanical properties by activating the post-cure phenomenon. However, beyond a certain temperature, the polymerization reaction reaches its maximum level and the heating becomes dangerous by leading to the glass transition of the resin.

- The exact value of the glass transition temperature of the resin cured at room temperature was determined by DSC tests. This Tg value was found around $62^{\circ} \mathrm{C}$. The superposition of DSC results with pull-out tests results showed that the resin glass transition is the main factor responsible for the decay in fire resistance of chemical anchors.

- The TGA test results showed that no changes in the resin chemical composition occur at temperatures lower than $150^{\circ} \mathrm{C}$. These results exclude the involvement of any chemical transformation phenomenon in the decay in fire resistance of chemical anchors. Nevertheless, TGA test highlighted a small resin mass loss (around $0.2 \%$ ) at temperatures comprised between $20^{\circ} \mathrm{C}$ and $150^{\circ} \mathrm{C}$ caused possibly by water vaporization, which according to a previous study [4] affects the stress redistribution along the anchor.

- The interpretation of results obtained from pull-out tests at constant load showed the influence of creep phenomenon in decreasing the mechanical properties of chemical anchors. This phenomenon could not unfortunately be quantified directly from these pull-out tests because of its interference with other phenomena such as post-cure and water vaporization.

- This paper succeeded in identifying the main phenomena affecting the mechanical behavior of chemical anchors in fire situation through various tests carried out at the scale of the materials and at the global scale of the anchor.

- The current method used to design chemical anchors in fire situation were criticized in this study. This paper highlighted a non-conservative aspect of the current design method due to the choice of the bond resistance criterion in determining the load bearing capacity of the anchor during fire exposure.

- This paper suggests a new design criterion based on the relative displacement of the anchor during pull-out tests, allowing to improve the current design method and to ensure a safer use of chemical anchors in fire situation.

\section{Acknowledgments}

The research experimental work discussed in this paper was conducted at the Fasteners Laboratory at C.S.T.B (Centre Scientifique et Technique du Bâtiment). The authors would like to acknowledge Mr. 
Christophe CANEZIN, head of fasteners laboratory at C.S.T.B and Mr. David CADOUX research engineer and head of the Laboratory Pipes, Fluids and Materials at C.S.T.B.

\section{References}

[1] P. Bardonnet, "Résines époxydes (EP) - Composants et propriétés," Traité plastiques et composites, éditions T.I. (Techniques de l'ingénieur), 1992.

[2] F. Hugenchmidt, "New experiences with epoxies for structural applications," Int J Adhes Adhes, vol. 2(2), pp. 84-95, April 1982.

[3] D. Van Gemart, "Force transfer in epoxy bonded steel/concrete joints," Int Adhes Adhes, vol. 1(2), pp. 67-72, October 1980.

[4] N. Pinoteau, P. Pimienta, T. Guillet, P. Rivillion and S. Rémond, "Effect of heating rate on bond failure of rebars into concrete using polymer adhesives to simulate exposure to fire," Int Adhes Adhes, vol. 31(8), pp. 851-861, December 2011.

[5] H. Sato, K. Fujikake and S. Mindess, "Study on dynamic pullout strength of anchors based on failure modes," 13th World Conference on Earthquake Engineering, vol. 854, August 1-6, 2004 Vancouver, B.C., Canada.

[6] L. Bouazaoui and A. Li, "Analysis of steel/concrete interfacial shear stress by means of pull out test," International Journal of Adhesion and Adhesives, vol. 28(3), pp. 101-108, 2008.

[7] E. Nigro, A. Bilotta, G. Cefarelli, G. Manfredi and E. Cosenza, "Performance under fire situations of concrete members reinforced with FRP rods: Bond models and design nomograms," Jornal of composites for construction, vol. 16, no. 4, pp. 395-406, August 2012.

[8] Y. Matsuzaki, "Ultimate Resistance of Anchor Bolts Installed in Concrete Members," Concrete Journal, Japan Concrete Institute, vol. 22(7), pp. 54-61, 1984.

[9] K. D. Zavliaris, S. Kollias and P. R. S. Speare, "An experimental study of adhesively bonded anchorages in concrete," Magazine of Concrete Research, 48, vol. 48(175), pp. 79-93, 1996.

[10] A. Colak, "Parametric study of factors affecting the pull-out strength of steel rods bonded into precast concrete panels," Int Adhes Adhes, vol. 21(6), pp. 489-493, 2001.

[11] A. Colak, "Estimation of ultimate tension load of methylmethacrylate bonded steel rods into concrete," Int Adhes Adhes, vol. 27(8), pp. 653-660, December 2007.

[12] R. Eligehausen and F. Werner, "Recent Developments and Open Problems in Fastening Technique," 2nd International Symposium on Connections between Steel and Concrete, Stuttgart, FIB, Germany; 2007.

[13] C. Higgins and R. Klingner, "Effect of environmental exposure on the performance of cast-inplace and retrofit anchors in concrete," ACl Struct J, vol. 95(5), pp. 506-517, 1998. 
[14] R. Cook and R. Konz, "Factors influencing bond strength of adhesive anchors," ACl Struc J, vol. 98(1), pp. 76-86, 2001.

[15] C. Tavares, M. Ribeiro, A. Ferreira and R. Guedes, "Creep behaviour of FRP-reinforced polymer concrete," Composite Structures, vol. 57, pp. 47-51, 2002.

[16] O. Elalaoui, E. Ghorbel, V. Mighot and M. Ben Ouezdou, "Mechanical and physical properties of epoxy polymer concrete after exposure to temperatures up to $250^{\circ} \mathrm{C}$," Construction and Building Materials, vol. 27, pp. 415-425, 2012.

[17] J. Reis, "Effect of Temperature on the Mechanical Properties of Polymer Mortars," Materials Research, vol. 15(4), pp. 645-649, 2012.

[18] R. Letsch, "Behaviour of polymers and polymer mortars at constant and changing temperatures," Proceedings of the 10th International Congress on Polymers in Concrete, Honolulu, Hawaii: 2001.

[19] R. Letsch, "Durability of Construction Materials: from materials science to construction materials engineering," Proceedings of First International Congress of RILEM, pp. 1107-1114, Versailles, France: 1987 .

[20] Construction Fixings association, "CFA Guidance Note: Fixings and Fire," August 1998.

[21] CEN, "EN 1991-1-2. Eurocode 1, Part 1-2: Actions on structures: general actions - actions on the structures exposed to fire," Bruxelles, Belgique; 2002.

[22] H. Spieth, J. Ozbolt, R. Eligehausen and J. Appl, "Numerical and Experimental Analysis of postinstalled rebar spiced with cast-in rebars," Proc. of 2 nd Int. Symp. on Connection between Steel and Concrete, pp. 889-898, Stuttgart 2007.

[23] CEN, "EN 1992-1-2 Eurocode 2. Part 1-2: Design of concrete structures - General rules Structural fire design," Bruxelles, Belgique; 2005.

[24] G. MUCIACCIA, A. CONSIGLIO and G. ROSATI, "Behavior and Design of Post-Installed Rebar Connections under Temperature," Key Engineering Materials, vol. 711, pp. 783-790, 2016.

[25] EOTA, "EAD 330087-00-0601, Systems for post-installed rebar connections with mortar," no. EOTA 14-33-0087-06.01, July 2015.

[26] R. Carbas, L. Da Silva and G. Critchlow, "Adhesively bonded functionnally graded joints by induction heating," International Journal of Adhesion and Adhesives, vol. 48, pp. 110-118, 2014.

[27] V. Mazurin, "Problems of Compatibility of the Values of Glass Transition Temperatures Published in the World Literature," Glass Physics and Chemistry, vol. 33(1), pp. 22-36, 2007.

[28] N. Pinoteau, PhD Thesis: Comportement des Scellements Chimiques d'Armatures Raportées pour Béton en Situation d'Incendie, Lille: Université Lille 1 (France), 2013. https://orinuxeo.univ-lille1.fr/nuxeo/site/esupversions/de94303f-5d72-4f61-9183-515ff08b490b 
[29] P. Chua and M. Piggott, "The Glass Fiber-Polymer Interface: I-Theoretical Consideration for Single Fiber Pull-out Tests," Composites Science and Technology, vol. 22, pp. 33-42, 1985.

[30] R. Tipireddy and S. Kumar, "http:\\dx.doi.org\10.1016/j.ijadhadh.2017.02.010," International Journal aof Adhesion and Adhesives, 2017.

[31] P. Upadhyaya and S. Kumar, "Pull-out capacity of adhesive anchors: An analytical solution," International Journal of Adhesion and Adhesives, vol. 60, pp. 54-62, 2015.

[32] P. Lawrence, "Some Theoretical Considerations of Fibre Pull-out from Elastic Matrix," Journal of Material Science, vol. 7, pp. 1-6, 1972.

[33] S. Kumar and M. Khan, "A shear-lag model for functionally graded adhesive anchors," Adhesion \& adhesives, vol. 68, pp. 317-325, 2016. 